\title{
The Economic Burden to Medicare of Stroke Events in Atrial Fibrillation Populations With and Without Thromboprophylaxis
}

\author{
Aarti A. Patel, PharmD, MBA, Kristine Ogden, BS, ${ }^{1}$ Mark Veerman, PharmD, \\ Samir H. Mody, PharmD, MBA, Winnie W. Nelson, PharmD, MS, MBA, and Nancy Neil, PhD ${ }^{3}$
}

\begin{abstract}
Some 3 million people in the United States have atrial fibrillation (AF). Without thromboprophylaxis, AF increases overall stroke risk 5-fold. Prevention is paramount as AF-related strokes tend to be severe. Thromboprophylaxis reduces the annual incidence of stroke in AF patients by 22\%-62\%. However, antithrombotics are prescribed for only about half of appropriate AF patients. The study team estimates the economic implications for Medicare of fewer stroke events resulting from increased thromboprophylaxis among moderate- to high-risk AF patients. The decision model used considers both reduced stroke and increased bleeding risk from thromboprophylaxis for a hypothetical cohort on no thromboprophylaxis (45\%), antiplatelets (10\%), and anticoagulation (45\%). AF prevalence, stroke risk, and stroke risk reduction are adjusted for age, comorbidities, and anticoagulation/antiplatelet status. Health care costs are literature based. At baseline, an estimated 24,677 ischemic strokes, 9127 hemorrhagic strokes, and 9550 bleeding events generate approximately $\$ 2.63$ billion in annual event-related health care costs to Medicare for every million AF patients eligible for thromboprophylaxis. A $10 \%$ increase in anticoagulant use in the untreated population would reduce stroke events by $9 \%$, reduce stroke fatalities by $9 \%$, increase bleed events by $5 \%$, and reduce annual stroke/bleed-related costs to Medicare by about $\$ 187$ million (7.1\%) for every million eligible AF patients. A modest $10 \%$ increase in the use of thromboprophylaxis would reduce event-related costs to Medicare by $7.1 \%$, suggesting a compelling economic motivation to improve rates of appropriate thromboprophylaxis. New oral anticoagulants offering better balance between the risks of stroke and major bleeding events may improve these clinical and economic outcomes. (Population Health Management 2014;17:159-165)
\end{abstract}

\section{Introduction}

$\mathbf{T}$ HERE ARE AN ESTIMATED 3 million adults in the United States with atrial fibrillation (AF), a number that is projected to increase to more than 12 million by the year 2050. ${ }^{1}$ The overall prevalence of AF in the Medicare population age 65 and older is about $6 \% .^{2}$ Prevalence varies substantially by age, ranging from about $0.1 \%$ among individuals younger than 55 years to as much as $12 \%$ among those 80 years and older. ${ }^{3}$ Currently about one third of US adults with AF are 80 years of age or older and, with the aging of the population, the proportion of US adults with AF older than age 80 is expected to climb to $53 \%$ by the year $2050{ }^{4}$
By itself $\mathrm{AF}$ is an important risk factor for stroke; overall, without thromboprophylaxis, individuals with AF have a 5 -fold increased risk of ischemic stroke. ${ }^{3,5}$ This risk is not uniform across AF patients; subpopulations have annual stroke rates that range from less than $2 \%$ to more than $18 \%{ }^{6}$ Prevention is paramount as AF-related strokes tend to be severe, are more likely to recur, and have higher mortality than strokes that are not AF-related. ${ }^{7,8}$

Meta-analyses have demonstrated that use of anticoagulants (eg, warfarin) and antiplatelet agents (acetylsalicylic acid, or ASA) reduces the risk of stroke by $22 \%-62 \%$ or more in patients with AF. ${ }^{9,10}$ Because the net benefit of thromboprophylaxis is related to the underlying risk of

\footnotetext{
${ }^{1}$ Janssen Scientific Affairs, LLC, Raritan, New Jersey.

${ }^{2}$ Oxford Outcomes, an ICON plc Company, San Francisco, California.

${ }^{3}$ Chordata Consulting, LLC and University of Washington, Seattle, Washington.

Results of an earlier analysis were presented as a poster at the AHA Epidemiology and Prevention/Nutrition, Physical Activity and Metabolism 2012 Scientific Sessions in San Diego, CA in March 2012.
} 
stroke, stroke risk classification schemes-such as the $\mathrm{CHADS}_{2}$ scoring algorithm-have been developed to facilitate risk stratification and selection of antithrombotic prophylaxis based on patient-specific risk of stroke. ${ }^{6}$ Published guidelines for stroke prevention in AF patients recommend treatment with ASA for patients with relatively lower stroke risk (lower $\mathrm{CHADS}_{2}$ scores) and warfarin for patients with relatively higher stroke risk (higher $\mathrm{CHADS}_{2}$ scores). ${ }^{1,12}$

Indeed, the incidence of AF-related stroke has declined in the last decade, in part because of the use of antithrombotic agents. Nevertheless, the World Health Organization estimates that the aging of the population and the increasing incidence of AF will increase the stroke burden-in terms of the number of disability-affected life years related to stroke as well as the health system costs associated with stroke events-in the decade to come. ${ }^{13}$

Despite the effectiveness of antithrombotic agents and their increased use since the early $1980 \mathrm{~s},{ }^{2,14,15}$ anticoagulation in the form of warfarin is prescribed for only about half of appropriate AF patients. ${ }^{16,17}$ Long-term use of warfarin in clinical practice is hampered by drug and food interactions, slow onset of action, requirement for close patient monitoring and regular dose adjustments, and individual variability in metabolism. ${ }^{18,19}$ Further, it is the nature of antithrombotic agents to increase bleeding risk; thus, the use of any thromboprophylaxis must balance the benefit of stroke prevention against the concomitant risk of bleeding. ${ }^{20}$
Nevertheless, the underuse of antithrombotic prophylaxis in appropriate patients with AF suggests that, although significant reductions in stroke incidence have been achieved, more strokes may be prevented with wider use of thromboprophylaxis. ${ }^{16}$ The goal of this study is to quantify this opportunity; specifically, to estimate the potential economic implications for traditional Medicare (Parts A and B) of fewer stroke events resulting from increased use of thromboprophylaxis monotherapy among AF patients at moderate-tohigh risk of stroke events.

\section{Methods}

A decision-analytic model was used to assess the annual economic burden of ischemic and hemorrhagic strokes resulting from underuse of antithrombotic agents in a hypothetical Medicare population of patients with AF who are candidates for thromboprophylaxis monotherapy. Decision analyses are commonly used to estimate the financial stream of consequences related to the uptake and diffusion of health technologies. ${ }^{21}$ Increasingly, decision analyses are sought out by those who manage and plan health care budgets, such as administrators of national or regional health care programs or private insurance plans.

The model begins with a hypothetical, age-representative population of 1 million Medicare patients with AF (Figure 1). ${ }^{15}$ Inputs for the baseline case (Table 1) were set to approximate

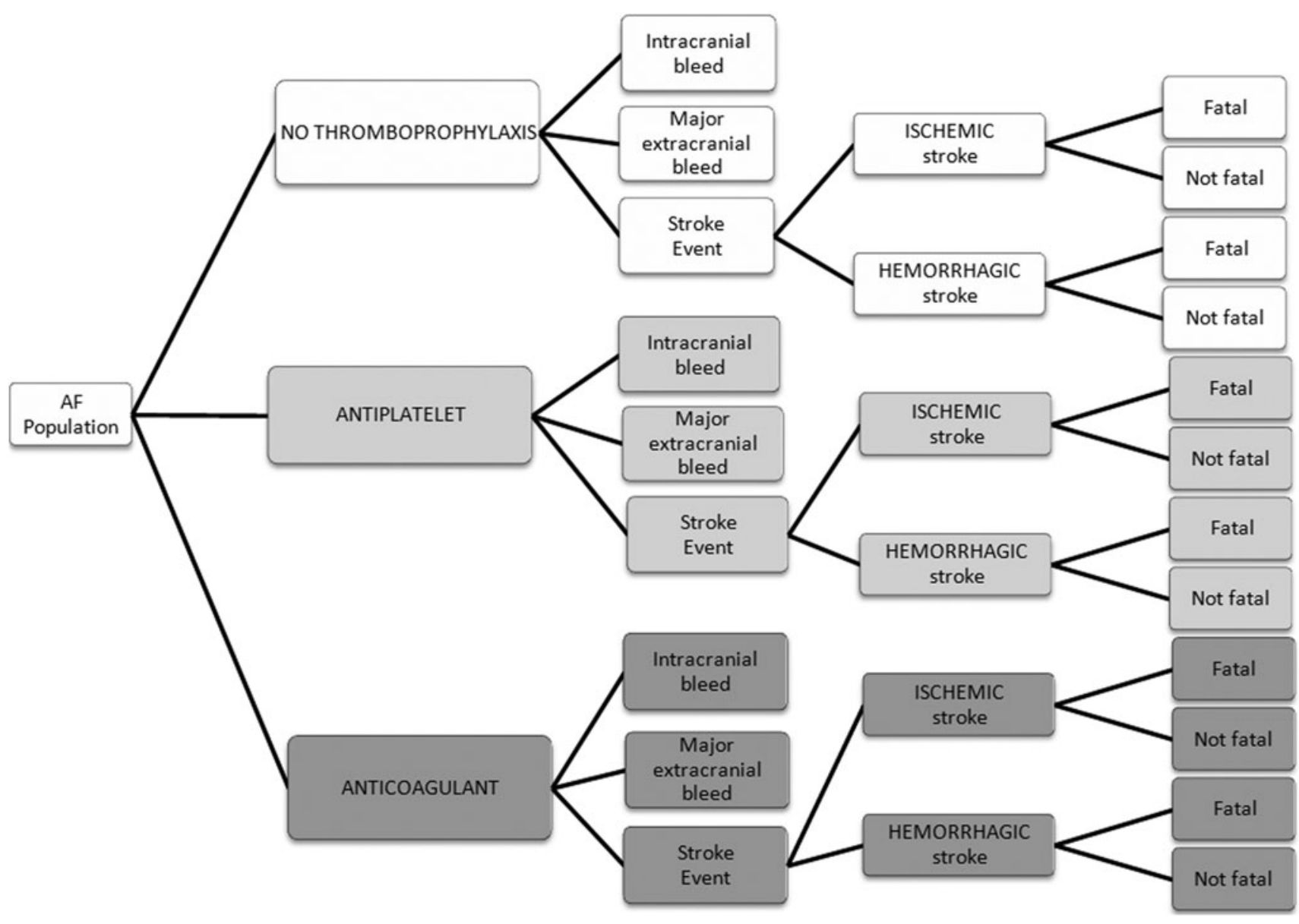

FIG. 1. Model schematic. AF, atrial fibrillation. 
Table 1. Baseline Model Inputs

\begin{tabular}{ll}
\hline Input variable & \multicolumn{1}{c}{ Baseline value } \\
\hline Age distribution & $<65(20.8 \%)$ \\
(Medicare adult & $65-74(43.5 \%)$ \\
population) & $75-84(25.7 \%)$ \\
& $\geq 85(10.0 \%)$ \\
AF prevalence & $<65(0.3 \%)$ \\
& $65-74(5.0 \%)$ \\
& $75-84(8.0 \%)$ \\
& $\geq 85(12.7 \%)$ \\
& \\
Antithrombotic use & No thromboprophylaxis $(45 \%)$ \\
& Antiplatelet $(10 \%)$ \\
& Anticoagulant $(45 \%)$ \\
Comorbid status & CHADS \\
& $0: 6.9 \%$ \\
& $1: 26.7 \%$ \\
& $2+: 66.4 \%$ \\
Stroke risk based on & CHADS \\
comorbid status and & - $0: 1.9 \%(1.2-3.0)$ \\
age (95\% CI) & - $1: 2.8 \%(2.0-3.8)$ \\
& - $2+: 5.96 \%(4.5-7.7)$
\end{tabular}

Risk reduction ( $R R$ ) by clinical management strategy (vs. no thromboprophylaxis)

Stroke risk based on $\mathrm{CHADS}_{2}$ score

RR Antiplatelet: $22 \%$ RR

RR Anticoagulant: $62 \%$ RR

Low (1.9\%)

Moderate $(2.8 \%)$

High (6.0\%)

Risk shown for $\mathrm{CHADS}_{2}$ (level $2+$ ) is a weighted average of rates given for $\mathrm{CHADS}_{2}$ (level 2 through level 6)

$\mathrm{CHADS}_{2}$ score:

- Low risk $=$ level 0

- Mod risk=level 1

- High risk= weighted average of rates given for $\mathrm{CHADS}_{2}$ (level 2 through level 6)

Distribution of stroke events

Intracranial and major extracranial bleed risk by clinical management strategy* these, $25(15.9 \%)$ were fatal within 30 days.

Hemorrhagic events: 58/211 (27\%). Of these, $23(40 \%)$ were fatal within 30 days.

No thromboprophylaxis:

- Absolute risk of intracranial bleed $=0.1 \%$

- Absolute risk of major extracranial bleed $=0.6 \%$
Ischemic events:

Patients having events: $73 \%$ 30-day fatalities: $15.9 \%$

Hemorrhagic events:

Patients having events: $27 \%$

30-day fatalities: $40 \%$

No thromboprophylaxis:

- Intracranial bleed $(0.1 \%)$

- Major extracranial bleed $(0.6 \%)$

Antiplatelets:

- Intracranial bleed $(0.2 \%)$

- Major extracranial bleed $(0.8 \%)$

Anticoagulants:

- Intracranial bleed $(0.3 \%)$

- Major extracranial bleed $(0.9 \%)$
Source

statehealthfacts.org. Distribution of Medicare beneficiaries by age, $2010 .^{22}$

Prevalence for patients $<65$ years (Ingenix I3 cohort analysis, data on file)

Prevalence for patients $\geq 65$ years: Mercaldi et al 2011, ${ }^{15}$ page 114 , column 1 .

Informed by Ogilvie et al $2010^{16}$ and Mercaldi $2011^{15}$

Gage et al $2001,{ }^{6}$ page 2867 , Table 2

Gage et al $2001^{6}$, page 2867 , Table 2

RR Antiplatelet: Hart et al 19999; page 496, column 2

RR Anticoagulant: Hart et al $1999^{9}$; page 495, column 2

Gage et al. 2001, ${ }^{6}$ page 2867 , Table 2

Ischemic events: $157 / 211(73 \%)$. Of Sherman et al 2005, ${ }^{23}$ page

Antiplatelets:

- Absolute risk of intracranial bleed $=0.2 \%$

- Risk of major extracranial bleed with no thromboprophylaxis $(0.6 \%)+$ absolute risk increase with antiplatelets $(0.2 \%)=0.8 \%$ calculated absolute risk of major extracranial bleed

Anticoagulants:

- Absolute risk of intracranial bleed $=0.3 \%$

- Risk of major extracranial bleed with no thromboprophylaxis $(0.6 \%)+$ absolute risk increase with anticoagulants $(0.3 \%)=0.9 \%$ calculated absolute risk of extracranial bleed 1187, Table 2

No thromboprophylaxis:

Hart et al 1999, p495, column 2

Antiplatelets:

- Intracranial bleed, Hart et al $1999,{ }^{9}$ page 497 , column 1

- Major extracranial bleed, Hart et al 2007, ${ }^{20}$ Table 5

Anticoagulants:

- Intracranial bleed, Hart et al $1999,{ }^{9}$ page 495 , column 2

- Major extracranial bleed, Hart et al 2007, ${ }^{20}$ Table 5 
TABle 1. (CONTINUED)

\begin{tabular}{|c|c|c|c|}
\hline Input variable & Baseline value & Calculation & Source \\
\hline Event costs & $\begin{array}{l}\text { Ischemic stroke: } \\
\text { - nonfatal }(\$ 76,232) \\
\text { - fatal }(\$ 14,314) \\
\text { Hemorrhagic stroke: } \\
\text { - nonfatal }(\$ 105,751) \\
\text { - fatal }(\$ 40,326) \\
\text { Intracranial bleed: } \$ 102,625 \\
\text { Major extracranial bleed: } \\
\quad \$ 6485\end{array}$ & $\begin{array}{l}\text { Non-fatal ischemic stroke: cost of } \\
\text { 1-time moderate-severe } \\
\text { neurologic event }(\$ 13,020)+11 \\
\text { months' cost }(@ \$ 5,120) \\
\text { following event. [2008 US\$] } \\
\text { Fatal ischemic stroke: cost of } \\
\text { 1-time moderate-severe } \\
\text { neurologic event }(\$ 13,020) \text {. } \\
\text { [2008 US\$] } \\
\text { Non-fatal hemorrhagic stroke: } \\
\text { assumed to be equivalent to the } \\
\text { cost of intracranial bleed. } \\
\text { Fatal hemorrhagic stroke: cost of } \\
\text { 1-time moderate-to-severe } \\
\text { neurologic event ( } \$ 36,680) \text {. } \\
\text { [2008 US\$] } \\
\text { Intracranial bleed: } 1 \text {-time cost of } \\
\text { ICH (\$36,680)+ 11 months' cost } \\
\text { (@ } \$ 5410) \text { following event. [2008 } \\
\text { US\$] } \\
\text { Major extracranial bleed: Median } \\
\text { 2010 payment for DRG } 378 \\
\text { (gastrointestinal hemorrhage with } \\
\text { complication; median cost, } \\
\text { Medicare) of \$6,294. [2010 US\$] }\end{array}$ & 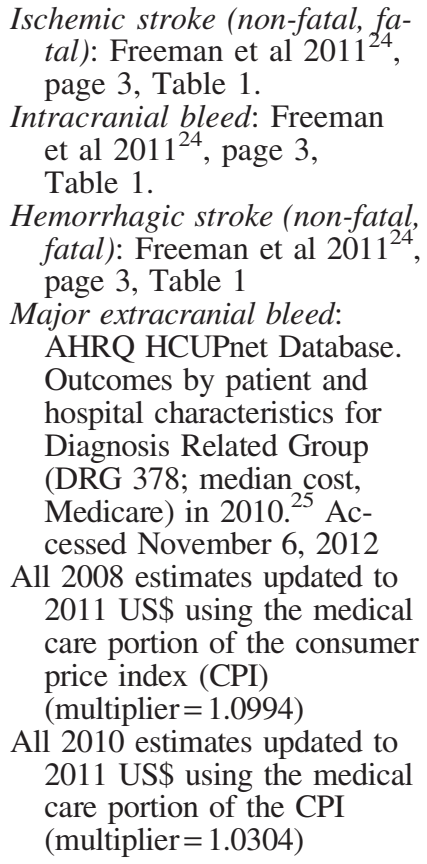 \\
\hline
\end{tabular}

*Estimates of ICH event rates supported by the most recent data available.

AF, atrial fibrillation; AHRQ, Agency for Healthcare Research and Quality; HCUP, Healthcare Cost and Utilization Project; ICH, intracranial hemorrhage.

current clinical treatment patterns for use of antithrombotic monotherapy for patients with $\mathrm{AF}$ and to represent the age distribution of a Medicare cohort. Specifically, the model assumes that patients with AF are managed clinically either with no thromboprophylaxis (45\%), ASA (10\%), or warfarin (45\%), a distribution that is consistent with studies of current management practices. ${ }^{16}$ Stroke risk (based on $\mathrm{CHADS}_{2}$ ) and stroke risk-reduction are adjusted for age, comorbidities, and anticoagulation/antiplatelet status. The stroke prevention benefits of thromboprophylaxis are balanced against the risk of bleeding in the model, specifically intracranial hemorrhages and major extracranial bleeds that require hospitalization and/or blood transfusion.

At baseline the model estimates the number of ischemic and hemorrhagic stroke events that might occur in each therapeutic cohort over a 1-year time horizon, as well as the number of those events that would result in fatality. In addition, the model estimates the annual stroke- and bleedrelated health care costs (2011 US\$) to Medicare, per million AF patients, based on the number of forecasted events and fatalities. A subsequent Increased Use analysis assesses the impact of a modest increase in the use of thromboprophylaxis on the incidence of stroke and bleed events, as well as the health care costs to Medicare associated with those events.

\section{Results}

Using baseline assumptions, Table 2 displays the model estimates of the numbers of ischemic strokes, hemorrhagic strokes, and major bleed events that will generate an estimated $\$ 2.63$ billion in stroke/bleed-related health care costs to Medicare annually for every million patients with AF who are eligible for thromboprophylaxis monotherapy.

A second analysis evaluated a $10 \%$ increase in the use of oral anticoagulants among the untreated population (ie, 35\% of appropriate AF patients receive no thromboprophylaxis; $10 \%$ are prescribed ASA; 55\% are prescribed warfarin),

Table 2. Model Results: Baseline Case Analysis (PER Million Eligible AF PATIENTS)

\begin{tabular}{lrrr}
\hline & $\begin{array}{c}\# \\
\text { Events }\end{array}$ & $\begin{array}{c}\# \\
\text { Fatal }\end{array}$ & \multicolumn{1}{c}{ Cost ${ }^{*}$} \\
\hline Ischemic stroke & 24,677 & 3,924 & $\$ 1,638,257,164$ \\
No thromboprophylaxis & 15,887 & 2,526 & \\
ASA & 2,754 & 438 & \\
warfarin & 6,037 & 960 & \\
Hemorrhagic stroke & 9,127 & 3,651 & $\$ 726,355,250$ \\
No thromboprophylaxis & 5,876 & 2,350 & \\
ASA & 1,018 & 407 & \\
warfarin & 2,233 & 893 & \\
Major extracranial bleed & 7,550 & - & $\$ 48,961,737$ \\
No thromboprophylaxis & 2,700 & - & \\
ASA & 800 & - & \\
warfarin & 4,050 & - & \\
Intracranial bleed & 2,000 & - & $\$ 211,501,943$ \\
No thromboprophylaxis & 450 & - & \\
ASA & 200 & - & \\
warfarin & 1,350 & - & \\
& & TOTAL & $\$ 2,625,076,094$ \\
& & &
\end{tabular}

*2011 US\$.

AF, atrial fibrillation; ASA, aspirin/antiplatelet therapy. 
Table 3. Model Results: Assuming a 10\% Increase in Anticoagulant Use From the Untreated population (per Million Eligible AF Patients)

\begin{tabular}{lrrr}
\hline & $\begin{array}{c}\# \\
\text { Events }\end{array}$ & $\begin{array}{c}\# \\
\text { Fatal }\end{array}$ & \multicolumn{1}{c}{ Cost ${ }^{*}$} \\
\hline Ischemic stroke & 22,489 & 3,576 & $\$ 1,492,946,800$ \\
No thromboprophylaxis & 12,356 & 1,965 & \\
ASA & 2,754 & 438 & \\
warfarin & 7,378 & 1,173 & \\
Hemorrhagic stroke & 8,318 & 3,327 & $\$ 661,928,890$ \\
No thromboprophylaxis & 4,570 & 1,828 & \\
ASA & 1,018 & 407 & \\
warfarin & 2,729 & 1,092 & \\
Major extracranial bleed & 7,850 & - & $\$ 50,907,236$ \\
No thromboprophylaxis & 2,100 & - & \\
ASA & 800 & - & \\
warfarin & 4,950 & - & \\
Intracranial bleed & 2,200 & - & $\$ 232,652,137$ \\
No thromboprophylaxis & 350 & - & \\
ASA & 200 & - & \\
warfarin & 1,650 & - & \\
& & TOTAL & $\$ 2,438,435,064$ \\
& & &
\end{tabular}

*2011 US\$.

AF, atrial fibrillation; ASA, aspirin/antiplatelet therapy.

keeping all other variables constant. Table 3 displays the model estimates of the numbers of ischemic strokes, hemorrhagic strokes, and bleed events for this scenario. Together, these events will generate an estimated $\$ 2.44$ billion in annual stroke/bleed-related health care costs to Medicare.

Thus, the model (Figure 2) projects that a $10 \%$ increase in warfarin use from the untreated population will reduce total (ischemic and hemorrhagic) stroke events by $9 \%$; reduce total stroke fatalities by $9 \%$; increase bleed events by $5 \%$; and reduce annual stroke/bleed-related costs to Medi- care by about $\$ 187$ million $(7.1 \%)$ for every million patients with AF (Figure 3).

\section{Sensitivity analysis}

The baseline model stratifies patient stroke risk using point estimates from the widely used $\mathrm{CHADS}_{2}$ classification scheme. ${ }^{6}$ Sensitivity analyses were run to evaluate the impact of lower and higher risk of stroke within the confidence limits of the reported $\mathrm{CHADS}_{2}$ point estimates, holding all other variables constant.

Using the lowest $\mathrm{CHADS}_{2}$ stroke risk estimates (1.2\% to $4.5 \%$; Table 1) in the model yielded $25 \%$ fewer stroke events (and 23\% lower associated costs) compared to baseline. Conversely, use of the highest $\mathrm{CHADS}_{2}$ stroke risk estimates (3.0\% to 7.7\%; Table 1) yielded $31 \%$ more stroke events (and $28 \%$ higher associated costs) compared to baseline. The estimated number and cost of bleeding events in these analyses was unchanged (vs. baseline), as was the relative impact of a $10 \%$ increased use of anticoagulation on stroke events, stroke fatalities, bleeding events, and total annual costs to Medicare.

\section{Discussion}

Patients with AF are at much higher risk of stroke, and stroke-related death than are individuals without AF. This risk is not homogeneous; rather, it varies widely based on patient-specific characteristics such as age, sex, and comorbid conditions. Published guidelines for stroke prevention for patients with $\mathrm{AF}$ recommend thromboprophylaxis for patients at moderate-to-high risk of stroke. ${ }^{11,12}$ Indeed, there is substantial evidence that antithrombotic prophylaxis decreases the risk of stroke in this population. ${ }^{2,7,22}$ This use of thromboprophylaxis must, however, be balanced against the risk of bleeding events, such as intracranial hemorrhage and major extracranial bleeding requiring hospitalization and/or blood transfusion. ${ }^{20}$

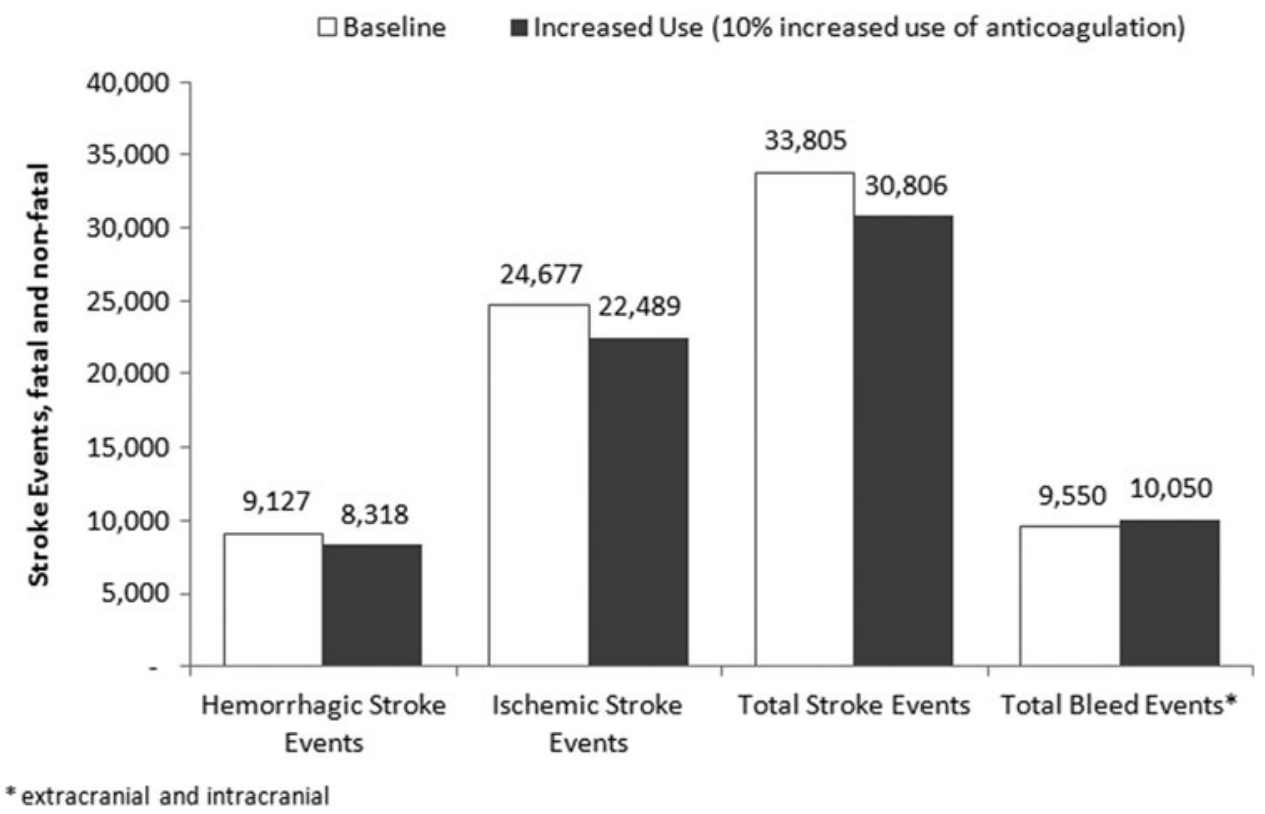

FIG. 2. Number of stroke and bleed events with $10 \%$ increased use of warfarin (per million eligible patients with atrial fibrillation). 


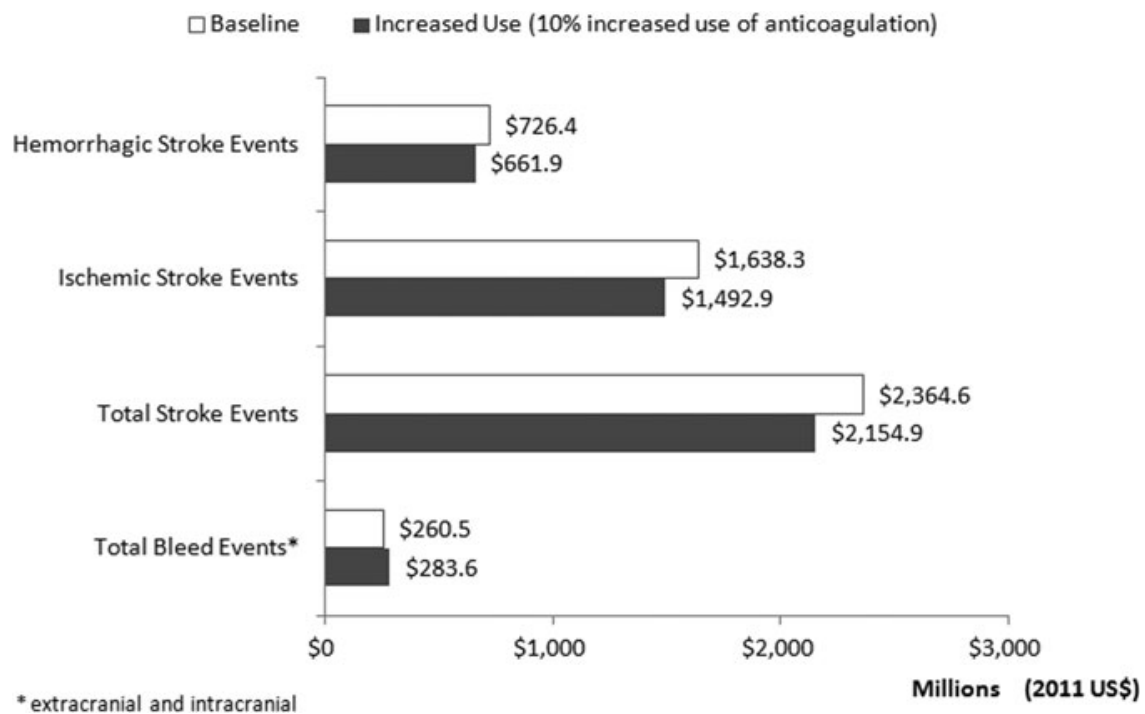

FIG. 3. Annual stroke-related and bleed-related costs to Medicare of $10 \%$ increased use of anticoagulation (per million eligible patients with atrial fibrillation).

The present analysis quantifies the opportunity represented by anticoagulation undertreatment in the population of patients with AF. A decision-analytic model was used to estimate the potential economic implications for traditional Medicare resulting from increased use of ASA and warfarin among a hypothetical cohort of moderate- to high-risk AF patients. The model considers the reduced stroke and increased bleeding risk implications of anticoagulation monotherapy as well as reduced stroke-related fatalities. Stroke risk, and stroke risk reduction are adjusted for age, comorbidities, and anticoagulation/antiplatelet status. Annual incremental stroke-related health care costs are drawn from published sources.

The approach uses the $\mathrm{CHADS}_{2}$ scoring algorithm to estimate stroke risk in patients with AF. Substantial, clinically relevant differences exist about how to stratify stroke risk appropriately in AF populations, and alternative scoring schemes may lead to different stroke risk estimates. Indeed, the recently introduced $\mathrm{CHA}_{2} \mathrm{DS}_{2}$-VASc schema ${ }^{23}$ could improve risk stratification in patients with AF; however, it has yet to be widely adopted in US clinical settings. Scoring algorithm differences also may foster confusion among practicing clinicians and result in the nonuniform use of antithrombotic therapies. ${ }^{24}$ Only about half of AF patients in clinical practice settings who are appropriate candidates for stroke prophylaxis receive treatment, despite the availability of effective therapies. ${ }^{16}$ This underuse of thromboprophylaxis in moderate- to high-risk AF patients could, if ameliorated, reduce preventable strokes and associated health care costs, morbidity, and mortality.

The present analysis forecasts that a modest $10 \%$ increase in the use of thromboprophylaxis would (1) reduce annual stroke/bleed-related dollar costs to Medicare by about $7.1 \%$ and (2) reduce stroke-related fatalities by $9 \%$, suggesting that there may be a compelling economic motivation to improve rates of appropriate use of antithrombotic agents in this population. Clinically, though, a $10 \%$ increase in the use of warfarin among the currently untreated population of moderate- to high-risk AF patients also would result in a $5 \%$ increase in major extracranial and intracranial bleed events. Regardless of any economic benefits, such an increase in bleed events is not to be taken lightly. Clinical trials provide evidence newly emerging oral anticoagulant agents (NOAC) have at least a similar effect on reducing stroke rates compared to warfarin with comparable or improved safety profiles. This may represent an opportunity to further reduce the cost of undertreatment as well as improve clinical outcomes in AF populations. ${ }^{25}$ This hypothesis should be evaluated in rigorous models of therapeutic costeffectiveness once data on the real-world performance of NOAC become available.

\section{Conclusion}

A modest $10 \%$ increase in the use of antithrombotic monotherapy among patients with AF would (1) reduce stroke/bleed event-related dollar costs to Medicare by $7.1 \%$ and (2) reduce stroke-related fatalities by $9 \%$ in this cohort, suggesting a potentially compelling economic motivation to improve rates of appropriate thromboprophylaxis. New oral anticoagulation agents offering better balance between the risks of stroke and major bleeds may further improve the clinical and economic outcomes of thromboprophylaxis in this population.

\section{Author Disclosure Statement}

Dr. Patel, Ms. Ogden, and Drs. Veerman, Mody, Nelson, and Neil declared the following potential conflicts of interest with respect to the research, authorship, and/or publication of this article: Dr. Neil and Ms. Ogden received consulting fees from Janssen Scientific Affairs, LLC for the development of this article. Drs. Patel, Veerman, Mody, and Nelson are employees of Janssen Scientific Affairs, LLC, a subsidiary of Johnson \& Johnson ( J\&J), and are shareholders of J\&J stock. This research was supported by Janssen Scientific Affairs, LLC, Raritan, New Jersey. 


\section{References}

1. Roger VL, Go AS, Lloyd-Jones DM, et al. Heart disease and stroke statistics-2012 update: a report from the American Heart Association. Circulation 2012;125(1): e2-e220.

2. Lakshminarayan K, Solid CA, Collins AJ, Anderson DC, Herzog CA. Atrial fibrillation and stroke in the general Medicare population: a 10-year perspective (1992 to 2002). Stroke 2006;37:1969-1974.

3. Lakshminarayan K, Anderson DC, Herzog CA, Qureshi AI. Clinical epidemiology of atrial fibrillation and related cerebrovascular events in the United States. Neurologist 2008;14(3):143-150.

4. Go AS, Hylek EM, Phillips KA, et al. Prevalence of diagnosed atrial fibrillation in adults: national implications for rhythm management and stroke prevention: the AnTicoagulation and Risk Factors in Atrial Fibrillation (ATRIA) Study. JAMA 2001;285(18):2370-2375.

5. Wolf PA, Abbott RD, Kannel WB. Atrial fibrillation as an independent risk factor for stroke: the Framingham Study. Stroke 1991;22:983-988.

6. Gage BF, Waterman AD, Shannon W, Boechler M, Rich MW, Radford MJ. Validation of clinical classification schemes for predicting stroke: results from the National Registry of Atrial Fibrillation. JAMA 2001;285(22):28642870.

7. Hart RG, Halperin JL, Pearce LA, et al. Lessons from the Stroke Prevention in Atrial Fibrillation trials. Ann Intern Med 2003;138:831-838.

8. Miller PS, Andersson FL, Kalra L. Are cost benefits of anticoagulation for stroke prevention in atrial fibrillation underestimated? Stroke 2005;36:360-366.

9. Hart RG, Benavente O, McBride R, Pearce LA. Antithrombotic therapy to prevent stroke in patients with atrial fibrillation: a meta-analysis. Ann Intern Med 1999;131: 492-501.

10. Agarwal S, Hachamovitch R, Menon V. Current trialassociated outcomes with warfarin in prevention of stroke in patients with nonvalvular atrial fibrillation: a metaanalysis. Arch Intern Med 2012;172:623-631; discussion 631-623.

11. Fuster V, Ryden LE, Cannom DS, et al. ACC/AHA/ESC 2006 guidelines for the management of patients with atrial fibrillation: a report of the American College of Cardiology/American Heart Association Task Force on Practice Guidelines and the European Society of Cardiology Committee for Practice Guidelines (Writing Committee to Revise the 2001 Guidelines for the Management of Patients With Atrial Fibrillation): developed in collaboration with the European Heart Rhythm Association and the Heart Rhythm Society. Circulation 2006;114(7):e257-e354.

12. Singer DE, Albers GW, Dalen JE, Go AS, Halperin JL, Manning WJ. Antithrombotic therapy in atrial fibrillation: the seventh ACCP conference on antithrombotic and thrombolytic therapy. Chest 2004;126(3 suppl):429S-456S.

13. World Health Organization (WHO). Part three: the burden; global burden of stroke. Geneva: World Health Organization (WHO), 2004.
14. Miyasaka Y, Barnes ME, Gersh BJ, et al. Time trends of ischemic stroke incidence and mortality in patients diagnosed with first atrial fibrillation in 1980 to 2000: report of a community-based study. Stroke 2005;36:2362-2366.

15. Mercaldi CJ, Ciarametaro M, Hahn B, et al. Cost efficiency of anticoagulation with warfarin to prevent stroke in Medicare beneficiaries with nonvalvular atrial fibrillation. Stroke 2011;42:112-118.

16. Ogilvie IM, Newton N, Welner SA, Cowell W, Lip GY. Underuse of oral anticoagulants in atrial fibrillation: a systematic review. Am J Med 2010;123:638-645.e4.

17. Goto S, Bhatt DL, Rother J, et al. Prevalence, clinical profile, and cardiovascular outcomes of atrial fibrillation patients with atherothrombosis. Am Heart J 2008;156(5): 855-863, 863.e2.

18. Go AS, Hylek EM, Borowsky LH, Phillips KA, Selby JV, Singer DE. Warfarin use among ambulatory patients with nonvalvular atrial fibrillation: the anticoagulation and risk factors in atrial fibrillation (ATRIA) study. Ann Intern Med 1999;131:927-934.

19. O'Brien CL, Gage BF. Costs and effectiveness of ximelagatran for stroke prophylaxis in chronic atrial fibrillation. JAMA 2005;293(6):699-706.

20. Hart RG, Pearce LA, Aguilar MI. Meta-analysis: antithrombotic therapy to prevent stroke in patients who have nonvalvular atrial fibrillation. Ann Intern Med 2007;146: 857-867.

21. Mauskopf JA, Sullivan SD, Annemans L, et al. Principles of good practice for budget impact analysis: report of the ISPOR Task Force on good research practices-budget impact analysis. Value Health 2007;10(5):336-347.

22. Darkow T, Vanderplas AM, Lew KH, Kim J, Hauch O. Treatment patterns and real-world effectiveness of warfarin in nonvalvular atrial fibrillation within a managed care system. Curr Med Res Opin 2005;21:1583-1594.

23. Pisters R, Nieuwlaat R, Lane DA, Crijns HJ, Lip GY. Potential net clinical benefit of population-wide implementation of apixaban and dabigatran among European patients with atrial fibrillation. A modelling analysis from the Euro Heart Survey. Thromb Haemost 2013;109:328-336.

24. Stroke Risk in Atrial Fibrillation Working Group. Comparison of 12 risk stratification schemes to predict stroke in patients with nonvalvular atrial fibrillation. Stroke 2008; 39:1901-1910.

25. Limone BL, Baker WL, Kluger J, Coleman CI. Novel anticoagulants for stroke prevention in atrial fibrillation: a systematic review of cost-effectiveness models. PloS One 2013;8(4):e62183.
Address correspondence to: Nancy Neil, PhD Senior Investigator

Chordata Consulting, LLC 4809 Osprey Dr. NE Tacoma, WA 98422

E-mail: nneil@chordataconsulting.com 